\title{
Airway-Centered Granulomatous Fibrinous and Organizing Pneumonia as a Manifestation of Sirolimus-A Reversible Pulmonary Toxicity
}

Andrews Arthur ${ }^{*}$, Sriaroon Chakrapol ${ }^{1}$, Rumbak Mark ${ }^{1}$, Prendes Barbara ${ }^{1}$, Johnson Jean ${ }^{2}$, Leslie Kevin ${ }^{3}$, Matta Amir $^{4}$ and Solomon David $^{1}$

${ }^{1}$ Division of Pulmonary, James A. Haley Veteran's Hospital, Tampa, Florida, USA

${ }^{2}$ Department of Pathology, James A. Haley Veteran's Hospital, Tampa, Florida, USA

${ }^{3}$ Department of Pathology, Mayo Clinic, Scottsdale, Arizona, USA

${ }^{4}$ St. Joseph's Medical Center, Kansas City, Missouri, USA

\begin{abstract}
Sirolimus is a potent immunosuppressant medication and is used in renal transplant patients to prevent acute graft rejection. Various pulmonary toxicities in patients treated with sirolimus include cough, desquamative interstitial pneumonia (DIP), diffuse interstitial pneumonia, diffuse alveolar damage (DAD), diffuse alveolar hemorrhage (DAH), alveolar phospholipoproteinosis and pulmonary hypertension with features of hemolytic uremic syndrome (HUS). We describe a case of a patient with an insidious development of chest X-ray (CXR), computed tomography of the chest (CT chest) and pulmonary function (PFT) (mainly the DLCO) abnormalities. When this progressed, an open lung biopsy was performed revealing granulomatous inflammation consistent with a hypersensitivity reaction. The abnormalities on imaging and pulmonary function testing improved after drug discontinuation. We suggest that patients using this drug have yearly DLCOs as their pulmonary symptoms may be few. If the DLCO declines significantly then a high resolution CT Chest should be performed. If abnormal, biopsy is warranted.
\end{abstract}

Keywords: Sirolimus; Rapamune; Granulomatous; Organizing pneumonia; Diffusing capacity

\section{Introduction}

Sirolimus is a potent immunosuppressant medication and is used in renal transplant patients to prevent acute graft rejection. The drug is non-nephrotoxic and works well when used with cyclosporine [1]. This has led to its expanded use [2]. The drug is a fermentation product of Streptomyces hygroscopicus and has immune-suppressive, antitumor and antifungal properties. By class it is a macro cyclic triene antibiotic and inhibits B- and T-cell activation by cytokine thereby preventing cell cycle progression and proliferation [3].

The more-well known side effects of sirolimus include thrombocytopenia, hypertension, edema, rash and hyperlipidemia [4]. Various pulmonary toxicities in patients treated with sirolimus include bronchiolitis obliterans organizing pneumonia (BOOP), desquamative interstitial pneumonia (DIP), diffuse interstitial pneumonia, diffuse alveolar damage (DAD), diffuse alveolar hemorrhage (DAH), alveolar phospholipoproteinosis, pulmonary hypertension with features of hemolytic uremic syndrome (HUS) [4].

We describe a case of a patient with an insidious development of chest X-ray (CXR), computed tomography of the chest (CT chest) and pulmonary function (PFT) abnormalities. When this progressed an open lung biopsy was performed. This revealed granulomatous inflammation consistent with a hypersensitivity reaction. The abnormalities on imaging and pulmonary function testing improved after drug discontinuation.

\section{Case Report}

A 56-year-old African American, male with a history of endstage renal disease, presented for evaluation of an abnormal CT scan of chest. His renal failure was initially managed with hemodialysis and a renal transplant followed this in 1988. The specific drugs used for his immunosuppression at that time are unknown. Thirteen years after transplant he experienced transplant rejection necessitating a second transplant in 2001. He served in the Air Force and was an air traffic controller for 11 years. He had no pets at home. His hobbies were swimming in his pool and singing. He did not use hot tubs. $\mathrm{He}$ was a rare drinker of alcohol-containing beverages. He did not smoke. He had well-controlled diabetes, hypertension, esophageal reflux, and hyperlipidemia.

Physical examination was noteworthy for a normal temperature of $98.4^{\circ} \mathrm{F}$, blood pressure of $130 / 90 \mathrm{mmHg}$, pulse of 88 beats per minute, respirations of 16 per minute and a room air oxygen saturation of $94 \%$. He was mildly obese with normal head and neck examination, no palpable adenopathy, and regular heart rhythm without murmurs, rubs or gallops. He had mid-ranged bibasilar and mid to posterior axillary line area rales with inspiration. Examination of the abdomen revealed the scars from the 2 surgeries and a palpable kidney in the right lower abdomen. There was no extremity cyanosis, clubbing or edema. Medications at the time were azathioprine, baclofen, Lasix, insulin, metoprolol, nifedipine, omeprazole, pravastatin, sertraline, sirolimus (since 2002) and valsartan. Laboratory studies at the time are shown in Table 1.

In the process of undergoing pre-operative evaluation for a trigger-release surgery involving the hand, a standard postero-anterior CXR revealed ill-defined opacities in the left lung base and left hilar region, which were new compared to a prior CXR (Figure 1). A CT scan of the chest noted patchy, peripheral and centrilobular airspace opacities predominantly involving the lower lungs bilaterally (Figure 2). Pulmonary function testing was performed using correction for race. Data collected were spirometry pre and post bronchodilator, lung volumes and diffusing capacity. This laboratory does not correct for

*Corresponding author: Arthur Andrews D, James A. Haley Veteran's Hospital 13000 Bruce B. Downs Blvd, Tampa, Florida 33612, USA, Tel: 813-972-2000; E-mail: aandrew1@hsc.usf.edu

Received September 12, 2015; Accepted July 18, 2016; Published July 22, 2016

Citation: Arthur A, Chakrapol S, Mark R, Barbara P, Jean J, et al. (2016) AirwayCentered Granulomatous Fibrinous and Organizing Pneumonia as a Manifestation of Sirolimus-A Reversible Pulmonary Toxicity. J Pulm Respir Med 6: 362. doi: 10.4172/2161-105X.1000362

Copyright: ( $) 2016$ Arthur A, et al. This is an open-access article distributed under the terms of the Creative Commons Attribution License, which permits unrestricted use, distribution, and reproduction in any medium, provided the original author and source are credited. 
Citation: Arthur A, Chakrapol S, Mark R, Barbara P, Jean J, et al. (2016) Airway-Centered Granulomatous Fibrinous and Organizing Pneumonia as a Manifestation of Sirolimus-A Reversible Pulmonary Toxicity. J Pulm Respir Med 6: 362. doi: 10.4172/2161-105X.1000362

\begin{tabular}{|c|c|c|c|}
\hline \multicolumn{3}{|c|}{ Urine drug screen negative } & \multirow[b]{2}{*}{ Reference Range } \\
\hline Test Name & Result & Units & \\
\hline Urine color & Yellow & & \\
\hline Appearance & Clear & & \\
\hline Specific gravity & 1.007 & & $1.002-1.030$ \\
\hline Uro QNT & 0.2 & $\mathrm{EU} / \mathrm{dl}$ & $0.1-1.0$ \\
\hline Urine Blood & Trace & & neg \\
\hline Urine Bilirubin & neg & & neg \\
\hline Urine Ketones & neg & & neg \\
\hline Urine Glucose & neg & & neg \\
\hline Urine Protein & neg & & neg \\
\hline Urine PH & 5 & & $4.5-8.0$ \\
\hline Urine Nitrite & neg & & neg \\
\hline Urine Leucocyte Esterase & neg & & neg \\
\hline Urine WBC/HPF & $<1 / \mathrm{HPF}$ & & $0-4$ \\
\hline $\mathrm{RBC} / \mathrm{HPF}$ & $<1 / \mathrm{HPF}$ & & $0-2$ \\
\hline Test Name & Result & Units & Reference Range \\
\hline Sodium & 140 & $\mathrm{meq} / \mathrm{L}$ & $136-145$ \\
\hline Potassium & 4.1 & $\mathrm{meq} / \mathrm{L}$ & $3.5-5.2$ \\
\hline Chloride & 109 & $\mathrm{meq} / \mathrm{L}$ & $98-109$ \\
\hline Glucose & 158 & $\mathrm{mg} / \mathrm{dl}$ & $65-110$ \\
\hline $\mathrm{CO}_{2}$ & 26 & $\mathrm{mmol} / \mathrm{L}$ & $22-32$ \\
\hline Urea Nitrogen & 22 & $\mathrm{mg} / \mathrm{dL}$ & Aug-23 \\
\hline EGFR* & 59 & & \\
\hline Creatinine & 1.5 & $\mathrm{mg} / \mathrm{dL}$ & $0.8-1.3$ \\
\hline Anion Gap & 5 & & $5-18$ \\
\hline Calcium & 9.1 & $\mathrm{mg} / \mathrm{dL}$ & $9.3-10.7$ \\
\hline Magnesium & 2.3 & $\mathrm{mg} / \mathrm{dL}$ & $1.8-2.5$ \\
\hline $\mathrm{PO}_{4}$ & 2.6 & $\mathrm{mg} / \mathrm{dL}$ & $2.3-4.3$ \\
\hline Total Protein & 7 & $\mathrm{~g} / \mathrm{dL}$ & $6.8-8.7$ \\
\hline ALBUMIN & 4.4 & $\mathrm{~g} / \mathrm{dL}$ & $4.1-5.3$ \\
\hline AST & 18 & $\mathrm{U} / \mathrm{L}$ & $16-43$ \\
\hline ALT & 16 & $\mathrm{U} / \mathrm{L}$ & $11-44$ \\
\hline ALK PHOS & 83 & $\mathrm{U} / \mathrm{L}$ & $25-125$ \\
\hline Total Bilirubin & 0.4 & $\mathrm{mg} / \mathrm{dL}$ & $.16-1.25$ \\
\hline Direct Bilirubin & 0.1 & & $0-0.40$ \\
\hline \multicolumn{4}{|c|}{ Estimated glomerular filtration rate } \\
\hline Test Name & Result & Units & Reference Range \\
\hline WBC & 8.2 & $\mathrm{G} / \mathrm{L}$ & $4.2-10.3$ \\
\hline RBC & 4.4 & $T / L$ & $4.2-5.8$ \\
\hline HGB & 13.3 & $\mathrm{~g} / \mathrm{dL}$ & $14-17$ \\
\hline HCT & 38.1 & $\%$ & $39-50$ \\
\hline MCV & 87.3 & $\mathrm{fl}$ & $80-100$ \\
\hline $\mathrm{MCH}$ & 30.4 & $\mathrm{pg}$ & $27-35$ \\
\hline $\mathrm{MCHC}$ & 34.8 & $g / d L$ & $32-36$ \\
\hline RDW & 15.2 & $\%$ & $11.3-14$ \\
\hline PLT & 229 & G/L & $150-410$ \\
\hline MPV & 7.2 & $\mathrm{fl}$ & $6.7-10.7$ \\
\hline NEUT & 6.7 & $\mathrm{G} / \mathrm{L}$ & $1.6-6.2$ \\
\hline Lymph & 0.7 & $\mathrm{G} / \mathrm{L}$ & $1.1-3.4$ \\
\hline MONO & 0.6 & $G / L$ & $0.3-0.9$ \\
\hline EOS & 0.1 & $\mathrm{G} / \mathrm{L}$ & $0.1-0.5$ \\
\hline BASO & 0.1 & $\mathrm{G} / \mathrm{L}$ & $0.0-0.1$ \\
\hline Specimen & Test name & Result & Units \\
\hline Blood & Sirolimus & 9.7 & Trough: $3.0-18$ \\
\hline
\end{tabular}

Table 1: Laboratory studies.

hemoglobin. Results revealed a mild restrictive ventilatory impairment with a severe reduction in the diffusing capacity for carbon monoxide (DLCO).

A 2-dimensional echocardiogram showed normal left ventricular

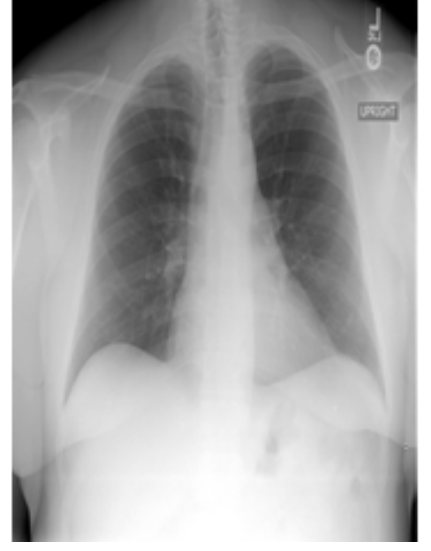

A

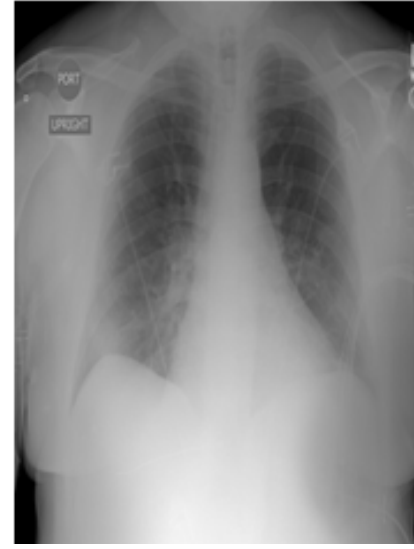

B
Figure 1: Chest X-ray before and after sirolimus. A) Chest X-ray before initiation of sirolimus was normal. B) Chest $\mathrm{X}$-ray while on sirolimus showing III-defined opacities are again noted within the right lung base and within the left hilar region which are new.

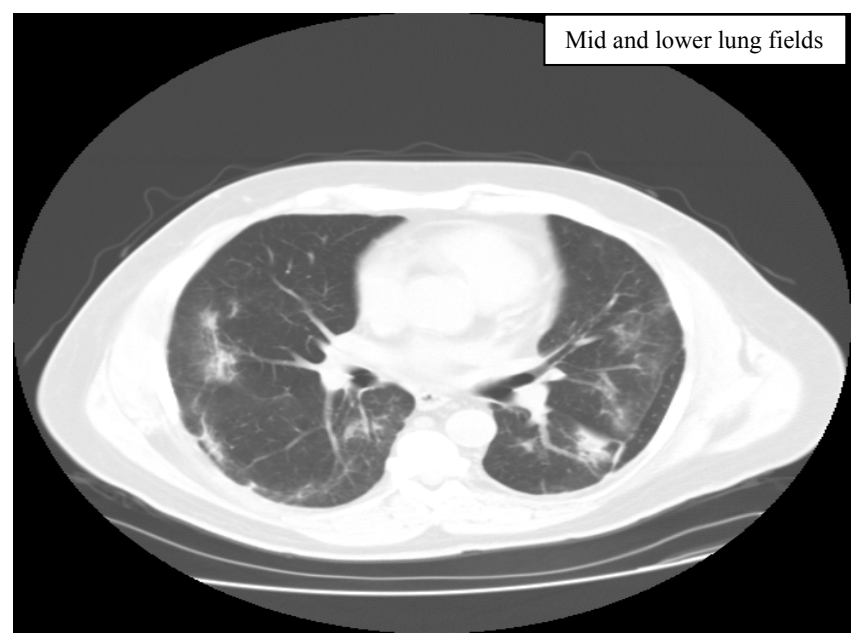

Figure 2: The initial CT scan of the chest showing the infiltrates. Lungs demonstrate patchy, peripheral and centrilobular air space opacities predominantly involving the lower lungs bilaterally.

function and size with ejection fraction of $55 \%$ to $60 \%$. There was mild concentric left ventricular hypertrophy with normal wall motion. The left atrial and right-sided chambers were normal in size. No diastolic dysfunction was appreciated. Estimated right ventricular systolic pressure was $25 \mathrm{mmHg}$ assuming right atrial pressure of 10 mmHg. A flexible fiber optic bronchoscopy (FOB) was performed with bronchoalveolar lavage from the lingula and the specimens were sent for immune-suppressed panel and cytology. These were globally negative. Acid-fast bacilli cultures remained negative at 6 weeks.

The patient was observed clinically for a 3-month period after which time a CT chest was repeated and revealed interval development of new patchy peripheral opacities and scattered reticular interstitial changes in the lower lobes (Figure 3). He had no new pulmonary symptoms. An open lung biopsy revealed an airway centered granulomatous inflammatory process suggestive of a hypersensitivity reaction (Figure 4). As the differential diagnosis for these findings included hypersensitivity pneumonitis and aspiration-related changes a barium swallow and dynamic video-esophogram were undertaken 
Citation: Arthur A, Chakrapol S, Mark R, Barbara P, Jean J, et al. (2016) Airway-Centered Granulomatous Fibrinous and Organizing Pneumonia as a Manifestation of Sirolimus-A Reversible Pulmonary Toxicity. J Pulm Respir Med 6: 362. doi: 10.4172/2161-105X.1000362
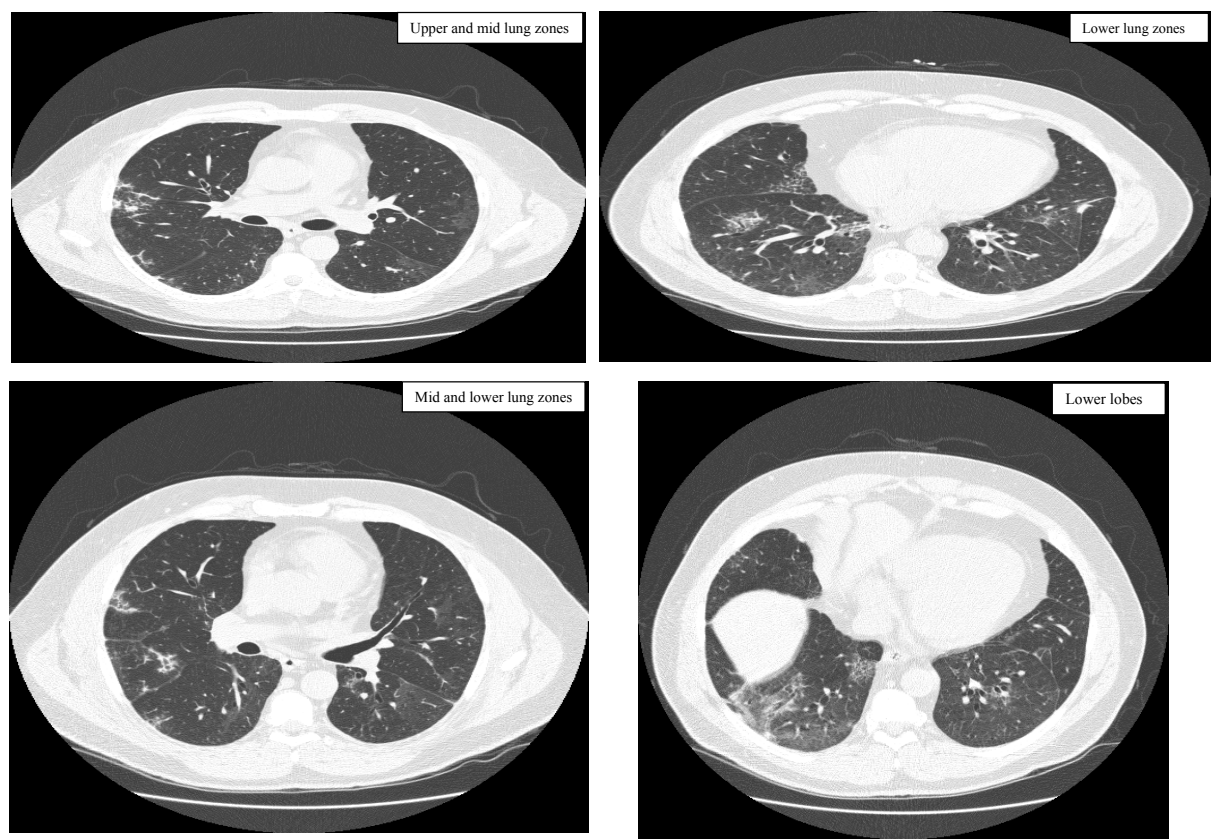

Figure 3: The second CT scan of chest three months later. The images obtained of the chest show interval improvement in most of the patchy peripheral air space opacities identified on prior examination. There has been however interval development of new patchy peripheral and reticular interstitial changes in both lower lobes.
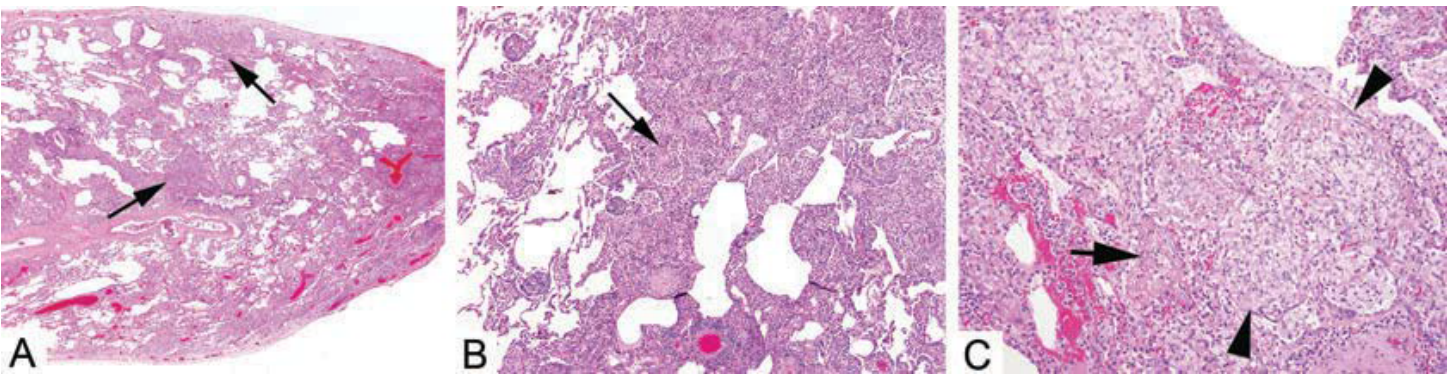

Figure 4: Surgical lung biopsy. Panel $A=12.5 X, B=100 X$, and $C=200 X$. A) At scanning magnification, nodular histiocytic and fibrinous exudates (arrows) can be seen involving peribronchiolar and subpleural parenchyma. Hematoxylin and eosin stain, $12.5 \mathrm{X}$ original magnification. $\mathrm{B})$ At higher magnification, multinucleated giant cells (arrow) and fibrin can be seen admixed with a pale vacuolated histiocytic reaction. Hematoxylin and eosin stain, $100 \mathrm{X}$ original magnification. C) Nodular poorly-formed granulomas are present (arrow heads). Focal aggregations of granular fibrin are seen (arrow). Hematoxylin and eosin stain, 200 X original magnification.

and were unremarkable. The sirolimus was discontinued. Azathioprine was continued. Transplant Nephrology requested the addition of prednisone $5 \mathrm{mg}$ daily to the suppression regimen. The infiltrates on $\mathrm{CT}$ chest and the PFT abnormalities began to improve. The CT chest and DLCO are shown at 4 months and 1 year respectively (Figure 5 and Table 2). The patient has continued to do well to current day with no pulmonary symptoms, resolution of opacities on standard CXR imaging and stable renal function. He remains on azathioprine and 5 mg daily prednisone immunosuppression.

\section{Pathology}

The surgical lung biopsy from the Right upper lobe shows the most findings, with nodular aggregations of fibrin with histiocytes formed into ill-defined granulomas. The lesions are distributed randomly in the parenchyma, some airway-centered, some lobular, and some in a subpleural location. The histiocytes have a pale vacuolated appearance with occasional included multinucleated giant cells. No necrosis is seen and parts of the lung biopsy are entirely spared. There are no areas of advanced fibrosis or microscopic honeycomb remodeling. Hematoxylin and eosin stains, $12.5 ; 100$, and 200x magnifications (Figure 4).

\section{Discussion}

Sirolimus is a highly effective immunosuppressant drug and is widely used in transplant medicine. It has been shown to be associated with several types of pulmonary toxicities including bronchiolitis obliterans organizing pneumonia (BOOP), desquamative interstitial pneumonia (DIP), diffuse interstitial pneumonia, diffuse alveolar damage (DAD), diffuse alveolar hemorrhage (DAH), alveolar phospholipoproteinosis and pulmonary hypertension with features of hemolytic uremic syndrome. Toxicity can also result in more common complaints such as cough [1]. It is noteworthy that the patient had few pulmonary symptoms of note and the early clinical clue was the significant decrement in the DLCO on PFTs in addition to progression of infiltrates on CT chest. Indeed, the onset and progression can be 
On drug

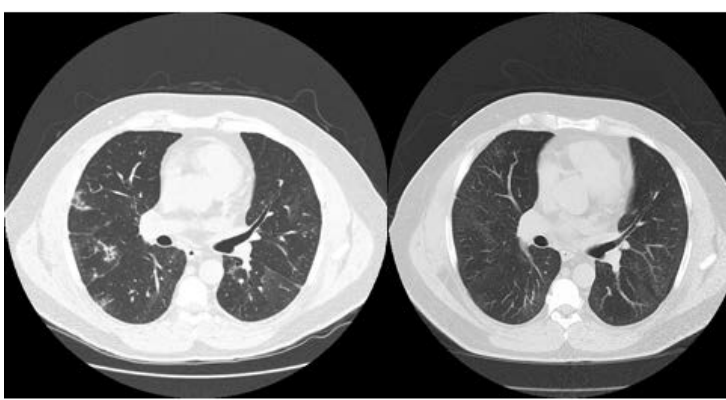

On drug

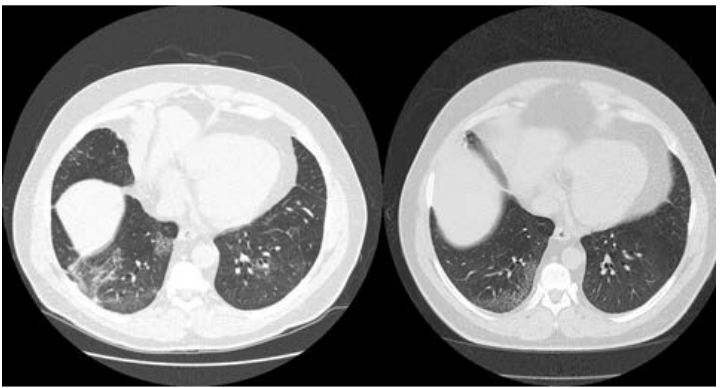

Figure 5: The CT scan of the chest 5 months after stopping the sirolimus patchy ground glass opacification and interstitial opacities in both lung bases which appear slightly improved when compared to the prior examination.

\begin{tabular}{|c|c|c|c|c|c|c|c|}
\hline \multicolumn{4}{|c|}{ On Drug } & \multicolumn{4}{|c|}{1 year Off Drug } \\
\hline Spirometry & Pred & Best & $\%$ Pred & Spirometry & Pred & Best & $\%$ Pred \\
\hline $\mathrm{FVC}(\mathrm{L})$ & 4.03 & 3.47 & 86 & $\mathrm{FVC}(\mathrm{L})$ & 4.01 & 3.54 & 88 \\
\hline $\mathrm{FEV}_{1}(\mathrm{~L})$ & 3.25 & 2.83 & 87 & $\mathrm{FEV}_{1}(\mathrm{~L})$ & 3.23 & 2.87 & 89 \\
\hline $\mathrm{FEV}_{1} / \mathrm{FVC} \%$ & 80 & 82 & & & & & \\
\hline \multicolumn{8}{|c|}{ Plethysmography Lung volumes } \\
\hline $\mathrm{VC}(\mathrm{L})$ & 4.03 & 3.52 & 87 & $\mathrm{VC}(\mathrm{L})$ & 4.01 & 3.56 & 89 \\
\hline TLC & 5.97 & 4.38 & 73 & TLC & 5.97 & 4.68 & 78 \\
\hline RV & 1.9 & 0.87 & 46 & $\mathrm{RV}$ & 1.9 & 1.12 & 58 \\
\hline RV/TLC\% & 32 & 20 & & RV/TLC\% & 32 & 24 & \\
\hline \multicolumn{8}{|l|}{ Diffusion } \\
\hline DLCO & 29.8 & 10.9 & 36 & DLCO & 29.6 & 15 & 51 \\
\hline DL/VA & 5.14 & 2.55 & 50 & DL/VA & 5.11 & 3.54 & 69 \\
\hline
\end{tabular}

Table 2: Pulmonary function tests.

insidious. Bronchoscopic bronchoalveolar lavage was negative for malignancy as well as infection. The differential cell count from the specimen revealed a lymphocytosis which is seen in the majority of patients with sirolimus pulmonary toxicity [2]. The patient discussed here was diagnosed with airway-centered granulomatous fibrinous and organizing pneumonia. This pathologic entity has been previously reported [3], however to our knowledge this is the first report of the use of DLCO and its derangement to guide management decisions. This patient responded to drug discontinuation and did not require high dose steroid treatment. This has been seen in prior reports of sirolimus pulmonary toxicity [4]. As noted in the case description the patient was maintained on prednisone $5 \mathrm{mg}$ daily. We do not believe that this dose of prednisone had a significant impact on the course of this patient's illness or the noted improvement after sirolimus discontinuation. We base this belief on the well verified data showing normal human cortisol production rates of $5 \mathrm{mg} / \mathrm{m}^{2} /$ day to $9 \mathrm{mg} / \mathrm{m}^{2} /$ day. This would equate to an oral prednisone dose of $5 \mathrm{mg}$ to $7 \mathrm{mg}$ [5].

Clinicians taking care of transplant or other patients taking sirolimus should be aware of this potential complication. We propose baseline and yearly measurement of DLCO in the patient population receiving this important and frequently used immune modulator. In some of the initial investigation into amiodarone pulmonary toxicity Magro et al. [6] found that the DLCO was perhaps the most reliable PFT parameter used in screening with a decrease of $\geq 15 \%$ being significant. In this patient we found a decrease in the absolute value of DLCO by $38 \%$ and percent predicted value of DLCO by $42 \%$. The measurement should be done in a laboratory well experienced with proper performance of the DLCO as erroneous measurement may adversely affect patient management. If the DLCO decreases significantly, a high resolution CT chest (HRCT) should be obtained. If it is also abnormal, an open lung or transbronchial cryo-biopsy should be considered.

\section{References}

1. Adibelli Z, Dilek M, Kocak B, Tulek O, Akpolat T (2007) An Unusual Presentation of Sirolimus Associated Cough In a Renal Transplant Recipient. Transplant Proc 39: 3463-3464.

2. Champion L, Stern M, Israel-Biet D, Mamzer-Bruneel M, Peraldi MN, et al. (2006) Brief Communication: Sirolimus-Associated Pneumonitis: 24 Cases in Renal Transplant Recipients. Ann Intern Med 144: 505-509.

3. Chhajed PN, Dickenmann M, Bubendorf L, Mayr M, Steiger J, et al. (2006) Patterns of Pulmonary Complications Associated with Sirolimus. Respiration 73: $367-374$.

4. Weiner SM, Sellin L, Vonend O, Schenker P, Buchner NJ, et al. (2007) Pneumonitis associated with sirolimus: clinical characteristics, risk factors and outcome-a single centre experience and review of the literature. Nephrol Dial Transplant 22: 3631-3637.

5. Coursin DB, Wood KE (2002) Corticosteroid Supplementation for Adrenal Insufficiency. JAMA 287: 236-240.

6. Magro SM, Lawrence EC, Wheeler SH, Krafchek J, Lin HT, et al. (1988) Amiodarone Pulmonary toxicity: Prospective evaluation of serial Pulmonary Function Tests. J Am Coll Cardiol 12: 781-788. 